\title{
Diagnostic value of routine dental radiographs for predicting the inferior alveolar nerve localization validated by CBCT measurements.
}

Bernhard Wiechens ( $\square$ bernhard.wiechens@med.uni-goettingen.de)

University Medical Center Göttingen: Universitatsmedizin Gottingen https://orcid.org/0000-0002-23235940

\section{Phillipp Brockmeyer}

University Medical Center Göttingen: Universitatsmedizin Gottingen

\section{Tayhan Sevinc}

University Medical Center Göttingen: Universitatsmedizin Gottingen

\section{Georg Hoene}

University Medical Center Göttingen: Universitatsmedizin Gottingen

\section{Henning Schliephake}

University Medical Center Göttingen: Universitatsmedizin Gottingen

\section{Wolfram Hahn}

University Medical Center Göttingen: Universitatsmedizin Gottingen

\section{Research Article}

Keywords: Panoramic radiograph, lateral cephalometric radiograph, cone-beam computed tomography, cephalometry, predictability of nerve location

Posted Date: February 11th, 2022

DOI: https://doi.org/10.21203/rs.3.rs-1329964/v1

License: (a) (1) This work is licensed under a Creative Commons Attribution 4.0 International License. Read Full License 


\section{Abstract \\ Purpose}

To test the hypothesis that routine dental radiographs can be used to draw conclusions regarding inferior alveolar nerve (IAN) localization.

\section{Methods}

A total of 108 radiographs (36 orthopantomograms [OPTs], 36 lateral cephalograms [LCs], and 36 conebeam computed tomograms [CBCTs]) of 36 patients were analyzed. Cephalometric parameters obtained through OPTs and LCs were correlated with CBCT scans for predictability of IAN localization.

\section{Results}

The IAN ran along the lingual half $(n=24)$ twice as often as in the buccal half $(n=12)$ in population of the study. The position was always symmetrical contralaterally. No sex-specific correlations were observed $(p=0.34)$. Lingual nerve courses correlated with enlarged and buccal courses with reduced jaw angles $(p=0.003 / p=0.010)$. An increased jaw angle was significantly correlated with a more cranial nerve position; a deep and distal bite position was significantly correlated with a caudal and buccal nerve position $(p=0.020)$. Moreover, an increase of 1 point in the Hasund score predicted an increased probability of a buccal nerve position by $18.6 \%$. The jaw angle analyzed in OPT, and LC images were positively correlated $(r=0.89, p<0.001)$.

\section{Conclusions}

Routine dental radiographs provide meaningful conclusions about IAN localization in the vertical and transverse dimension prior CBCT scans. This finding could be used during the initial consultation and treatment planning to weigh more invasive diagnostic methods further down the line.

\section{Introduction}

Lateral cephalograms (LCs) and orthopantomograms (OPTs) are indispensable for orthodontic diagnosis and treatment planning $[1,27]$. Cephalometric analysis and the relationships among the jaws, dentition, and soft tissues provide essential information about the pathogenesis of dental malocclusions $[1,27]$. However, heretofore, there is no consensus on the diagnostic value or justifiable indication of LCs and OPTs, as some studies critically question the validity of cephalometric analysis and the influence on orthodontic treatment decisions. This is primarily because of the fact that no clear and universal definition of basic radiological diagnostics for orthodontic treatment can be found in the extant literature $[1,10,11,21,25,27]$. Radiological diagnostics are associated with radiation exposure of the patient, 
which can be considerable even at low doses [6, 13]. Particularly in the case of children, who make up the largest proportion of patients undergoing orthodontic treatment, it must therefore be well considered whether and which radiological technique should be used $[10,25]$. The aforementioned routine dental radiological imaging techniques (LCs and OPTs) provide a wealth of information in terms of incidental findings that are rarely recorded, interpreted, and used for further treatment in everyday practice [4]. For example, they can help locate the inferior alveolar nerve (IAN) position, which is of particular importance during extraction or osteotomy of wisdom teeth and during insertion of temporary anchorage devices to avoid nerve damage $[19,20,23]$. Haas and colleagues [15] remarked in the systematic review and metaanalysis that the diagnosability of the nerve position in OPT should be investigated, as some studies have shown a prevalence of $1 \%$ in OPTs [8,22], whereas in cone-beam computed tomogram (CBCT) scans, nerve position abnormalities were found in up to $30 \%$ cases [15]. Therefore, this study was conducted with the aim of investigating the diagnostic value of routine two-dimensional dental radiographic procedures (OPTs and LCs) in relation to IAN position. The results could be used in the initial consultation and treatment planning to justify more advanced radiation-intensive three-dimensional radiographic imaging techniques (CBCTs).

\section{Material And Methods}

\section{Patients}

This retrospective analysis was conducted in accordance with the principles of the Declaration of Helsinki and was approved by an Institutional Ethics Committee. Written consent to use radiographs for scientific purposes was obtained from each patient.A total of 108 radiographs ( 36 OPTs, 36 LCs, and 36 CBCTs) of 36 patients were analyzed. OPTs were obtained during routine dental, oral, and maxillofacial surgical diagnostics and therapy planning. LCs were obtained for orthodontic cephalometric analysis and treatment planning. The patient population consisted of 20 women and 16 men, with ages ranging from 18 to 51 years (mean age 25.8 years). The averaged skeletal parameters of the study population are encapsulated in Table 1. All data were collected in the period from March 2019 to July 2020 and analyzed by two independent experienced investigators. Study inclusion criteria were completed bone growth, and a circumferent supported natural dentition. Exclusion criteria were craniofacial malformations, already performed maxillomandibular advancement, bone trauma, and diseases of the jaw bases.

\section{Radiological evaluation}

All data were evaluated by two independent investigators and were tested for normal distribution using Shapiro-Wilk tests. Subsequently, inter-rater reliability was confirmed using Bland-Altman plots (Table 2). In each OPT, the mean value of both jaw angles (Mand.Ang.) was determined. In addition, the average distances of the root tips of the second molars of both quadrants (RT7) to the mandibular base were measured (Figure 1). All OPTs were evaluated using the SIDEXIS XG® software (Sirona Dental Systems $\mathrm{GmbH}$, Bensheim, Germany). 
In each LC, eight different angles were measured (see Figure 2). The ratio of the anterior facial heights (index) was determined using Hasund's cephalometric analysis, and a structural analysis of the mandible was performed according to the method proposed by Björk and modified by Segner and Hasund $[3,17$, 28]. The entire cephalometric analysis was performed using the ivoris ${ }^{\circledR}$ analyze software (Computer Konkret AG, Falkenstein, Germany).

All CBCT scans were analyzed using the Ez3D Plus ${ }^{\circledR}$ software (Vatech Company, Hwaseong, Korea). The vertical distance between the IAN and the occlusal bone surface was determined at three different measuring points (MN1 to MN3) over a length of $20 \mathrm{~mm}$, starting distal in direction to the second mandibular molar. The measuring points MN1 to MN3 were thus located at a distance of exactly 10 or 20 $\mathrm{mm}$ from each other (Figure 3). In addition to the vertical position of the IAN, the transverse position was examined and divided into two groups. For this purpose, a distance of $5 \mathrm{~mm}$ distal to the second mandibular molar was marked in the axial view of the СВCT scans (Figure 4). In accordance with this distance, a coronal view could be set, which served to evaluate the nerve position (Figure 5). Data were divided into two groups depending on whether the nerve ran in the lingual or buccal half of the mandibular bone (Figure 5, Table 3).

\section{Statistical analysis}

Statistical analysis was performed using Student's t-test, chi-square test, linear regression, logistic regression with backward removal algorithm, and Pearson correlation. All tests were performed at a significance level of $a=5 \%$, using the statistical software STATISTICA $®$ (StatSoft Europe GmbH, Hamburg, Germany) and SPSS ${ }^{\circledR}$ (IBM Corporation, New York, USA).

\section{Results}

\section{Inter-rater variations}

Table 2 summarizes the results of the Bland-Altman plots. The largest range of inter-rater variation was found for the NSBa parameter, where $95 \%$ of the measurement differences between the two raters were in a range of $-3.91 \mathrm{~mm}$ and $3.44 \mathrm{~mm}$. Considering the other parameters, a low inter-rater variability could be assumed.

\section{Descriptive statistics}

The averaged skeletal configuration of the patients showed a bimaxillary orthognathic configuration, with sagittal and vertical neutral jaw relation, neutral maxillary and mandibular base inclination, neutral skull base inclination, and neutral index and jaw angle (Table 1). The mean inferior bone height was 25.39 $\mathrm{mm}$, and the mean vertical nerve position ranged from $10.26 \mathrm{~mm}$ (MN1) to $12.30 \mathrm{~mm}$ (MN3).

\section{Significance of cephalometric parameters for nerve localization}


Table 3 presents the results of the applied t-test to analyze the correlations between the cephalometric measurements of the LC/OPT images and the buccal or lingual IAN position according to the CBCT scans. The cephalometric NSBa angle (LC) and the mandibular angle (Mand.Ang.; OPT) correlated significantly with each other ( $p=0.039$ and $p=0.010$, respectively). Thus, a decreased NSBa angle or an increased mandibular angle predicted a lingual IAN position, while an increased NSBa angle and a decreased mandibular angle indicated a buccal nerve position. The inclination of the mandibular angle (GnGoAr) and the extent of the Hasund score measured in the LC confirmed this relationship with a strongly significant expression $(p=0.003 ; p=0.006)$. Moreover, a lingual nerve position was also correlated with an increased jaw angle and a reduced Hasund score, whereas a reduced jaw angle and an increased Hasund score resulted in a buccal nerve position.

\section{Relevance of jaw angle and bite relation for nerve localization}

Table 4 summarizes the significant results of the Pearson correlation analysis between the LC and CBCT measurements. All measurement points of the vertical nerve position in the CBCT scans were significantly negatively correlated with the sagittal mandibular position according to the LC (SNB). In retral mandibular positions (decreased SNB), increased distances between the nerve position and the occlusal cortical bone could be determined. Accordingly, the nerve position was caudal in retral located mandibles and cranial in anterior located mandibles. The negative correlation was significant for the measurement points MN1 and MN3 ( $p=0.040$ and $p=0.012$, respectively) and strongly significant for measurement point MN2 $(p=0.006)$. The correlation analysis of the skeletal configuration confirmed the

previously described relationship according to which increased deviations of the mandibular bases in the sagittal plane (ANB) were associated with an increase of the measurement points MN1 to MN3 (Figure 6). The positive correlation was strongly significant for measurement points MN1 and MN2 $(p=0.003 ; p$ $=0.001)$ and significant for point MN3 $(p=0.044)$. Measuring point MN3 was negatively correlated with the jaw angle $(p=0.004)$ and positively correlated with the Hasund score $(p=0.002)$. A decreased (increased) jaw angle and an increased (decreased) Hasund score thus allowed caudal nerve position to be detected and vice versa.

\section{Relationship between mandibular base and nerve localization}

The RT7 value (OPT) was positively correlated with a vertical IAN position in the CBCT scans (MN1, MN2, and MN3: $p=0.002, p=0.001$, and $p=0.013$, respectively) (Table 5, Figure 7). Thus, an increased RT7 distance suggested an increase in $\mathrm{MN1}-\mathrm{MN} 3$ readings on $\mathrm{CBCT}$, suggesting a more caudal nerve localization. This observation was supported by the negative correlation of the mandibular angle (Mand.Ang.) and the most posterior measurement point MN3 (CBCT). With reduced jaw angles, significantly increased distances, and thus more caudal nerve positions were found $(p=0.013)$.

\section{Relevance of mandibular structure for nerve localization}

The influence of all parameters on the observed correlations of the nerve position was tested using logistic regression analysis with a backward removal algorithm (Table 6). For a buccal nerve position, the 
analysis revealed an odds ratio of 1.186 for the Hasund score. Thus, the relative chance of the IAN being positioned in the buccal half of the mandible at the position examined increased by $18.6 \%$ when the Hasund score increased by $1(p=0.020)$.

\section{Correlation between LC and OPT measurements}

A strong positive correlation between the jaw angles measured in LC and OPT could be observed $(r=0.89$; $p=<0.001 ;$ Table 4, Figure 8).

\section{Discussion}

In this investigation, we performed a cephalometric analysis on routine dental two-dimensional radiographic techniques (OPT and LC) and compared them with the data obtained from CBCT scans to predict the inferior alveolar nerve position. The results indicated a close correlation of various parameters of the less radiation-intensive standard techniques with those of CBCT scans. From this, extended benefits for OPT and LC imaging can be established because of the additional informative value regarding the nerve localization $[7,16,18]$. This could be of particular interest during the initial consultation and treatment planning and to justify more radiation-intensive three-dimensional imaging techniques. To date, no study can be found in the literature on the established correlations and combinations of findings for the localization of the IAN nerve. Using the dedicated knowledge about the individual cephalometry of the patient (LC) and the configuration of the mandibular base (OPT), it was observed that relevant statements about the nerve position can already be made in the initial diagnostic process. Compared to the more radiation-intensive three-dimensional methods, the combination of both two-dimensional imaging techniques yielded information with a high correlation. In addition, further correlations could be determined by the structural analysis method, according to Björk $[3,17]$. For the first time, direct relationships between the morphological characteristics of the mandible and the nerve position could be determined in a specific question [5]. The diagnostic benefit lay in the combination of findings, which can already find special application in the initial orthodontic therapy planning. Skeletal anchorage devices are being used more and more frequently $[2,24,29,30]$. The retromolar region not only offers biomechanically favorable conditions for extensive en-masse dental arch retractions $[2,24]$ but also has the closest positional relationship to the IAN $[2,24,29,30]$, representing a high risk for nerve injuries [9]. As described earlier [9], nerve injuries could be avoided without the use of radiation-intensive three-dimensional imaging.

Moreover, the osteotomy of impacted third molars can lead to IAN damage [14]. Guerrero et al. [14] investigated the incidence of IAN lesions during third molar extraction using OPT or CBCT navigation and did not find significant differences in postoperative complications between both techniques. At the same time, however, the authors pointed out that the bucco-lingual nerve position can be easily determined using CBCT scans, which is a clear advantage of three-dimensional imaging. The results of the present investigation revealed that a statement about the IAN bucco-lingual position can also be made by combining the findings of the LC. Other studies have addressed the significance of OPT compared with 
CBCT but never combined with LC. A systematic review and meta-analysis by Reia et al. [26] found accuracy values for IAN position using CBCT of $95.1 \%$ for sensitivity $(p=0.666)$ and $64.4 \%$ for specificity $(p<0.001)$ and for OPT $73.9 \%(p=0.101)$ to $24.8 \%(p<0.001)$. The authors remarked that both techniques reliably detected the IAN position, but the CBCT examination achieved better performance in predicting the IAN position during surgery. However, the results of the present study on IAN position suggested a correction, especially regarding the sensitivity of OPTs because of their ability to predict nerve position in bucco-lingual direction. In contrast, Ghaeminia et al. [12] concluded that CBCTs were not more accurate in predicting IAN position during third molar removal but clarified the possibility of threedimensional imaging of the third molar root to the mandibular channel. However, the authors also affirmed the possibility of using coronal slices to perform a bucco-lingual assessment of the mandibular channel on CBCT scans to identify cases in which a lingually placed IAN is at risk during surgery.

\section{Conclusion}

Strong correlations between cephalometric parameters in OPT and LC images and data obtained from CBCT scans, regarding the inferior alveolar nerve position, were found. Considering these results, it would be safe to say that the diagnostic value of two-dimensional imaging needs to be reevaluated and could guide decisions regarding the future indication of more extensive three-dimensional imaging techniques.

\section{Declarations}

\section{Acknowledgements}

We would like to thank Ms. Maria Stark for her assistance in the conduct of the statistical analysis.

\section{Funding}

Open Access funding enabled and organized by Projekt DEAL.

\section{Availability of data and materials}

The data underlying this article are available from the corresponding author on reasonable request.

\section{Ethics approval and consent to participate}

The Ethics Committee of the University Medical Center Goettingen, Germany approved this study (application number DOK_342_2015). All patients gave their written informed consent to participate.

\section{Consent for publication}

Not applicable.

\section{Competing interests}


The authors have no competing interests to declare that are relevant to the content of this article.

\section{Author Contribution}

Conceptualization: [Wolfram Hahn], [Tayhan Sevinc]; Methodology: [Wolfram Hahn], [Tayhan Sevinc]; Formal analysis and investigation: [Wolfram Hahn], [Tayhan Sevinc], [Bernhard Wiechens], [Phillipp Brockmeyer]; Writing - original draft preparation: [Bernhard Wiechens], [Phillipp Brockmeyer]; Writing review and editing: [Henning Schliephake], [Georg Hoene].

\section{References}

1. American Academy of Oral and Maxillofacial Radiology (2013) Clinical recommendations regarding use of cone beam computed tomography in orthodontics. corrected. Position statement by the American Academy of Oral and Maxillofacial Radiology. Oral surgery, oral medicine, oral pathology and oral radiology 116:238-257

2. Anhoury PS (2013) Retromolar miniscrew implants for Class III camouflage treatment. Journal of clinical orthodontics : JCO 47:706-715

3. Björk A (1969) Prediction of mandibular growth rotation. American Journal of Orthodontics 55:585599

4. Bondemark L, Jeppsson M, Lindh-Ingildsen L, Rangne K (2006) Incidental findings of pathology and abnormality in pretreatment orthodontic panoramic radiographs. The Angle orthodontist 76:98-102

5. Bremen J von, Pancherz H (2005) Association between Björk's structural signs of mandibular growth rotation and skeletofacial morphology. The Angle orthodontist 75:506-509

6. Brenner DJ (2009) Extrapolating radiation-induced cancer risks from low doses to very low doses. Health physics 97:505-509

7. Bruks A, Enberg K, Nordqvist I, Hansson AS, Jansson L, Svenson B (1999) Radiographic examinations as an aid to orthodontic diagnosis and treatment planning. Swedish dental journal 23:77-85

8. Correr GM, Iwanko D, Leonardi DP, Ulbrich LM, Araújo MR de, Deliberador TM (2013) Classification of bifid mandibular canals using cone beam computed tomography. Brazilian oral research 27:510516

9. Denio D, Torabinejad M, Bakland LK (1992) Anatomical relationship of the mandibular canal to its surrounding structures in mature mandibles. Journal of endodontics 18:161-165

10. Devereux L, Moles D, Cunningham SJ, McKnight M (2011) How important are lateral cephalometric radiographs in orthodontic treatment planning. American journal of orthodontics and dentofacial orthopedics : official publication of the American Association of Orthodontists, its constituent societies, and the American Board of Orthodontics 139:e175-81

11. Durão AR, Alqerban A, Ferreira AP, Jacobs R (2015) Influence of lateral cephalometric radiography in orthodontic diagnosis and treatment planning. The Angle orthodontist 85:206-210 
12. Ghaeminia H, Meijer GJ, Soehardi A, Borstlap WA, Mulder J, Bergé SJ (2009) Position of the impacted third molar in relation to the mandibular canal. Diagnostic accuracy of cone beam computed tomography compared with panoramic radiography. International journal of oral and maxillofacial surgery 38:964-971

13. Ghorbani Z, Fardid R (2021) Effects of Low-dose Gamma Radiation on Expression of Apoptotic Genes in Rat Peripheral Blood Lymphocyte. Journal of biomedical physics \& engineering 11:693700

14. Guerrero ME, Botetano R, Beltran J, Horner K, Jacobs R (2014) Can preoperative imaging help to predict postoperative outcome after wisdom tooth removal? A randomized controlled trial using panoramic radiography versus cone-beam CT. Clinical oral investigations 18:335-342

15. Haas LF, Dutra K, Porporatti AL et al (2016) Anatomical variations of mandibular canal detected by panoramic radiography and CT: a systematic review and meta-analysis. Dento maxillo facial radiology 45:20150310

16. Kapetanović A, Oosterkamp BCM, Lamberts AA, Schols JGJH (2021) Orthodontic radiology: development of a clinical practice guideline. La Radiologia medica 126:72-82

17. Lenza MA, Carvalho AA de, Lenza EB, Lenza MG, Torres HM de, Souza JB de (2015) Radiographic evaluation of orthodontic treatment by means of four different cephalometric superimposition methods. Dental press journal of orthodontics 20:29-36

18. Mattick CR, Carter NE, Gordon PH (1999) The diagnostic value of routine intra-oral premaxillary radiographs in orthodontic assessment. International journal of paediatric dentistry 9:161-168

19. Matzen LH, Villefrance JS, Nørholt SE, Bak J, Wenzel A (2020) Cone beam CT and treatment decision of mandibular third molars: removal vs. coronectomy-a 3-year audit. Dento maxillo facial radiology 49:20190250

20. Matzen LH, Wenzel A (2015) Efficacy of CBCT for assessment of impacted mandibular third molars: a review - based on a hierarchical model of evidence. Dento maxillo facial radiology 44:20140189

21. Nijkamp PG, Habets LLMH, Aartman IHA, Zentner A (2008) The influence of cephalometrics on orthodontic treatment planning. European journal of orthodontics 30:630-635

22. Oliveira-Santos C de, Souza PHC, Azambuja Berti-Couto S de et al (2012) Assessment of variations of the mandibular canal through cone beam computed tomography. Clinical oral investigations 16:387-393

23. Patil S, Matsuda Y, Nakajima K, Araki K, Okano T (2013) Retromolar canals as observed on conebeam computed tomography: their incidence, course, and characteristics. Oral surgery, oral medicine, oral pathology and oral radiology 115:692-699

24. Poletti L, Silvera AA, Ghislanzoni LTH (2013) Dentoalveolar class III treatment using retromolar miniscrew anchorage. Progress in orthodontics 14:7

25. (2004) Radiation Protection no 136. European guidelines on radiation protection in dental radiology.

26. Reia VCB, Toledo Telles-Araujo G de, Peralta-Mamani M, Biancardi MR, Rubira CMF, Rubira-Bullen IRF (2021) Diagnostic accuracy of CBCT compared to panoramic radiography in predicting IAN 
exposure: a systematic review and meta-analysis. Clinical oral investigations 25:4721-4733

27. Rischen RJ, Breuning KH, Bronkhorst EM, Kuijpers-Jagtman AM (2013) Records needed for orthodontic diagnosis and treatment planning: a systematic review. PloS one 8:e74186

28. Segner D, Hasund A (2003) Individualisierte Kephalometrie. Segner, Hamburg

29. Sugawara Y, Kuroda S, Tamamura N, Takano-Yamamoto T (2008) Adult patient with mandibular protrusion and unstable occlusion treated with titanium screw anchorage. American journal of orthodontics and dentofacial orthopedics : official publication of the American Association of Orthodontists, its constituent societies, and the American Board of Orthodontics 133:102-111

30. Yanagita T, Kuroda S, Takano-Yamamoto T, Yamashiro T (2011) Class III malocclusion with complex problems of lateral open bite and severe crowding successfully treated with miniscrew anchorage and lingual orthodontic brackets. American journal of orthodontics and dentofacial orthopedics : official publication of the American Association of Orthodontists, its constituent societies, and the American Board of Orthodontics 139:679-689

\section{Tables}

Table 1: Descriptive statistics for all measurements of the LC, OPT and CBCT. The values SNA, SNB, ANB, ML-NSL, NL-NSL, ML-NL, NSBa, Gn-Go-Ar and Mand. Ang. are given in degrees. The index is given in percent. The Hasund value is given in ordinal score, RT7 and MN1 to 3 are given in mm. 


\begin{tabular}{lllllll} 
LC & & & & & & \\
\hline Parameter & Unit & $\mathrm{n}$ & mean & minimum & maximum & SD \\
\hline SNA & $\circ$ & 36 & 80,16 & 68,70 & 90,90 & 5,26 \\
\hline SNB & $\circ$ & 36 & 78,16 & 62,70 & 94,25 & 8,28 \\
\hline ANB & $\circ$ & 36 & 1,88 & -14 & 12,60 & 6,23 \\
\hline ML-NSL & $\circ$ & 36 & 33,26 & 10,05 & 51,25 & 10,43 \\
\hline NL-NSL & $\circ$ & 36 & 9,11 & 1,20 & 21,55 & 4,55 \\
\hline ML-NL & $\circ$ & 36 & 24,15 & 2,15 & 42,65 & 9,22 \\
\hline NSBa & $\circ$ & 36 & 131,89 & 117,85 & 168 & 9,30 \\
\hline Gn-Go-Ar & $\circ$ & 36 & 125,33 & 103,05 & 138,95 & 8,57 \\
\hline Index & $\%$ & 36 & 77,36 & 64 & 101 & 7,97 \\
\hline Hasund & score & 36 & 2,47 & -12 & 17 & 6,96 \\
\hline OPT & & & & & & \\
\hline Mand. Ang. & $\circ$ & 36 & 127,50 & 111,08 & 140,40 & 7,20 \\
\hline RT7 & mm & 36 & 13,19 & 7,50 & 20,53 & 3,28 \\
\hline CBCT & & & & & & \\
\hline MN1 & mm & 36 & 11,09 & 5,55 & 16,60 & 2,63 \\
\hline MN2 & mm & 36 & 10,26 & 4,95 & 16,50 & 3,12 \\
\hline MN3 & mm & 36 & 12,30 & 7,05 & 22,00 & 3,90
\end{tabular}

Table 2: Results of Bland-Altman plots on PR, LCR, and CBCT evaluation of both independent investigators. Angles are given in degrees [ $\left[^{\circ}\right.$, index in percent [\%] and Hasund as [score]. 


\begin{tabular}{lccl} 
Parameter & Unit & Lower Limit of Agreement & Upper Limit of Agreement \\
\hline Mand.Ang. & $\circ$ & -1.85 & 1.89 \\
\hline SNA & $\circ$ & -1.14 & 1.04 \\
\hline SNB & $\circ$ & -1.51 & 2.41 \\
\hline ANB & $\circ$ & -3.25 & 2.49 \\
\hline ML-NSL & $\circ$ & -1.55 & 1.78 \\
\hline NL-NSL & $\circ$ & -0.92 & 1.19 \\
\hline ML-NL & $\circ$ & -1.44 & 1.4 \\
\hline NSBa & $\circ$ & -3.91 & 3.44 \\
\hline Index & $\%$ & -2.31 & 1.84 \\
\hline Gn-Go-Ar & $\circ$ & -2.06 & 2.04 \\
\hline Hasund & score & -1.39 & 1.34
\end{tabular}

Table 3: T-tests for examining the cephalometric measurements as the independent variable and the nerve course as the dependent variable. The significance level was $p=<0.05$. Only the statistically significant parameters are given. ${ }^{*}=p<0.05 ;{ }^{*}=p<0.01$.

\begin{tabular}{lllllll} 
Parameter & Unit & $\begin{array}{l}\text { bucc. nerve course } \\
\text { (mean) }\end{array}$ & $\begin{array}{l}\text { ling. nerve course } \\
\text { (mean) }\end{array}$ & p-value & $\begin{array}{l}\text { bucc. } \\
\text { course (n) }\end{array}$ & $\begin{array}{l}\text { ling. } \\
\text { course } \\
(\mathrm{n})\end{array}$ \\
\hline $\mathrm{NSBa}$ & $\circ$ & 136.36 & 129.65 & $0.039 *$ & 12 & 24 \\
\hline Gn-Go-Ar & $\circ$ & 119.65 & 128.18 & $0.003^{\star *}$ & 12 & 24 \\
\hline Mand.Ang. & $\circ$ & 123.25 & 129.62 & $0.010^{*}$ & 12 & 24 \\
\hline Hasund & score & 6.83 & 0.29 & $0.006^{\star *}$ & 12 & 24
\end{tabular}

Table 4: Pearson correlations between LC and CBCT measurements of the retromolar region, as well as LC and OPT measurements. ${ }^{*}=p<0.05 ;{ }^{*}=p<0.01 ; * \star *=p<0.001$. 
Correlations between LC and CBCT measurements

\begin{tabular}{lllll}
\hline LC & Unit & CBCT (retromolar) & correlation coefficient & p-value \\
\hline SNB & $\circ$ & MN1 & -0.34 & $0.040^{\star}$ \\
\cline { 3 - 5 } & & MN2 & -0.45 & $0.006^{\star \star}$ \\
\cline { 3 - 5 } & MN3 & -0.41 & $0.012^{\star}$ \\
\hline ANB & $\circ$ & MN1 & 0.49 & $0.003^{\star \star}$ \\
\cline { 3 - 5 } & & MN2 & 0.57 & $0.001^{\star \star}$ \\
\cline { 3 - 5 } & & MN3 & 0.34 & $0.044^{\star}$ \\
\hline Gn-Go-Ar & $\circ$ & MN3 & -0.47 & $0.004^{\star \star}$ \\
\hline Hasund & score & MN3 & 0.50 & $0.002^{\star \star}$
\end{tabular}

Correlations between LC and OPT measurements

$\begin{array}{lllll}\text { LC } & \text { Unit } & \text { OPT } & \text { correlation coefficient } & \text { p-value } \\ \text { Gn-Go-Ar } & \circ & \text { Mand.Ang. } & 0.89 & <0.001^{\star \star \star}\end{array}$

Table 5: Pearson correlations between OPG measurements and DVT measurements in the retromolar region. ${ }^{*}=p<0.05 ; * \star p<0.01$.

\begin{tabular}{lllll} 
OPT & Unit & CBCT (retromolar) & correlation coefficient & p-value \\
\hline RT7 & $\mathrm{mm}$ & MN1 & 0.51 & $0.002^{\star \star}$ \\
\cline { 3 - 5 } & & MN2 & 0.54 & $0.001^{\star \star}$ \\
\cline { 3 - 5 } & & MN3 & 0.41 & $0.013^{\star}$ \\
\hline Mand.Ang. & $\circ$ & MN3 & -0.41 & $0.013^{\star}$
\end{tabular}

Table 6: Logistic regression with backward removal algorithm to study the influence of cephalometric parameters on nerve course in buccal position. For a buccal nerve course, an odds ratio of 1.186 is available for the Hasund score. The marginal probability that the nerve is located in the buccal half of the mandible at the examined position increases by $18.6 \%$ when the Hasund score is increased by $1 .{ }^{*}=p<$ 0.05 . 


\begin{tabular}{|lll|}
\hline Parameter & Odds Ratio & p-Wert \\
\hline Hasund [score] & 1.186 & $0.020 *$ \\
\hline
\end{tabular}

\section{Figures}

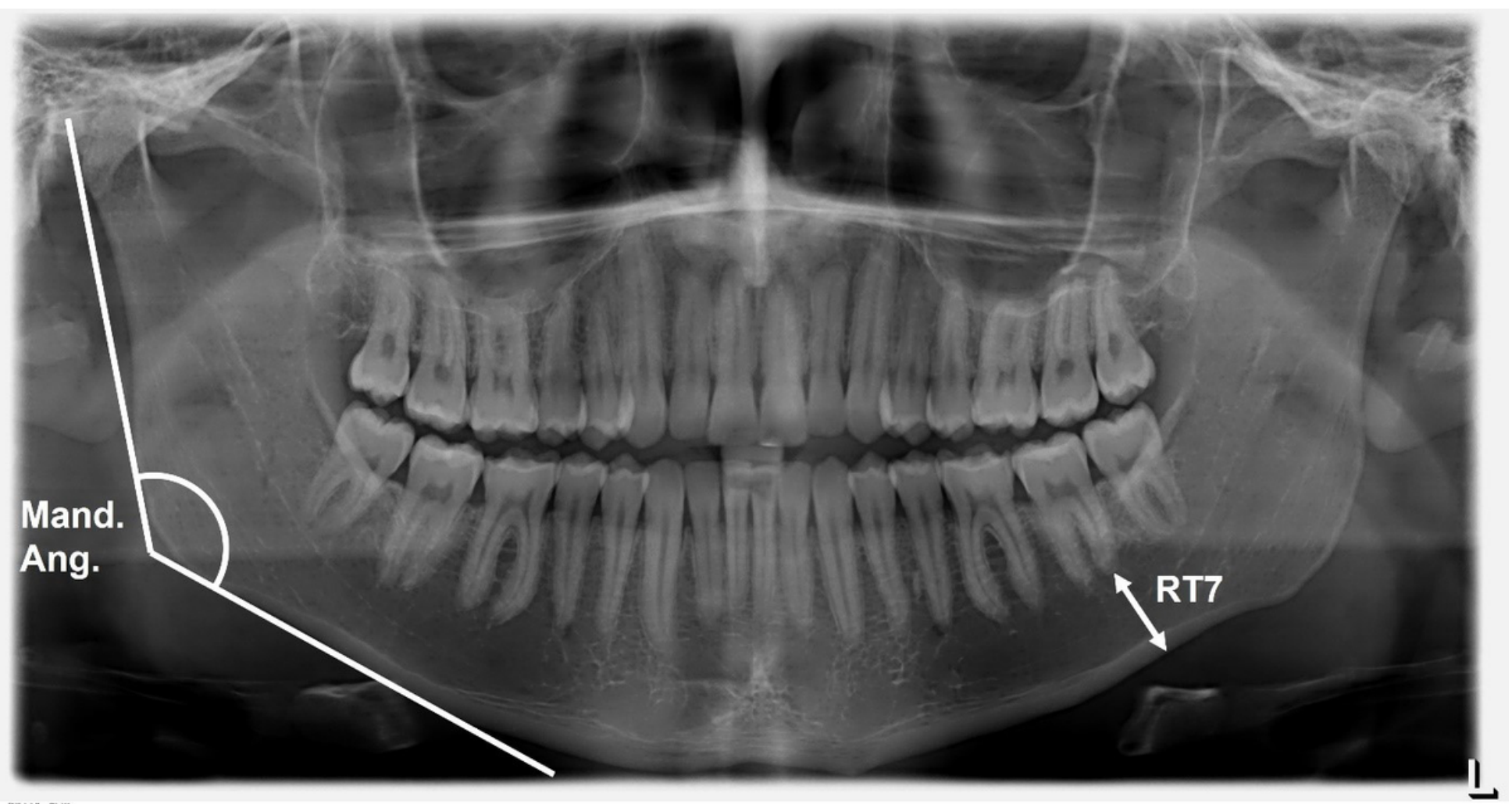

\section{Figure 1}

OPT with acquired measurements. Distance of the root tip of the second molar (RT7) to the mandibular base and the jaw angle (Mand.Ang.). 


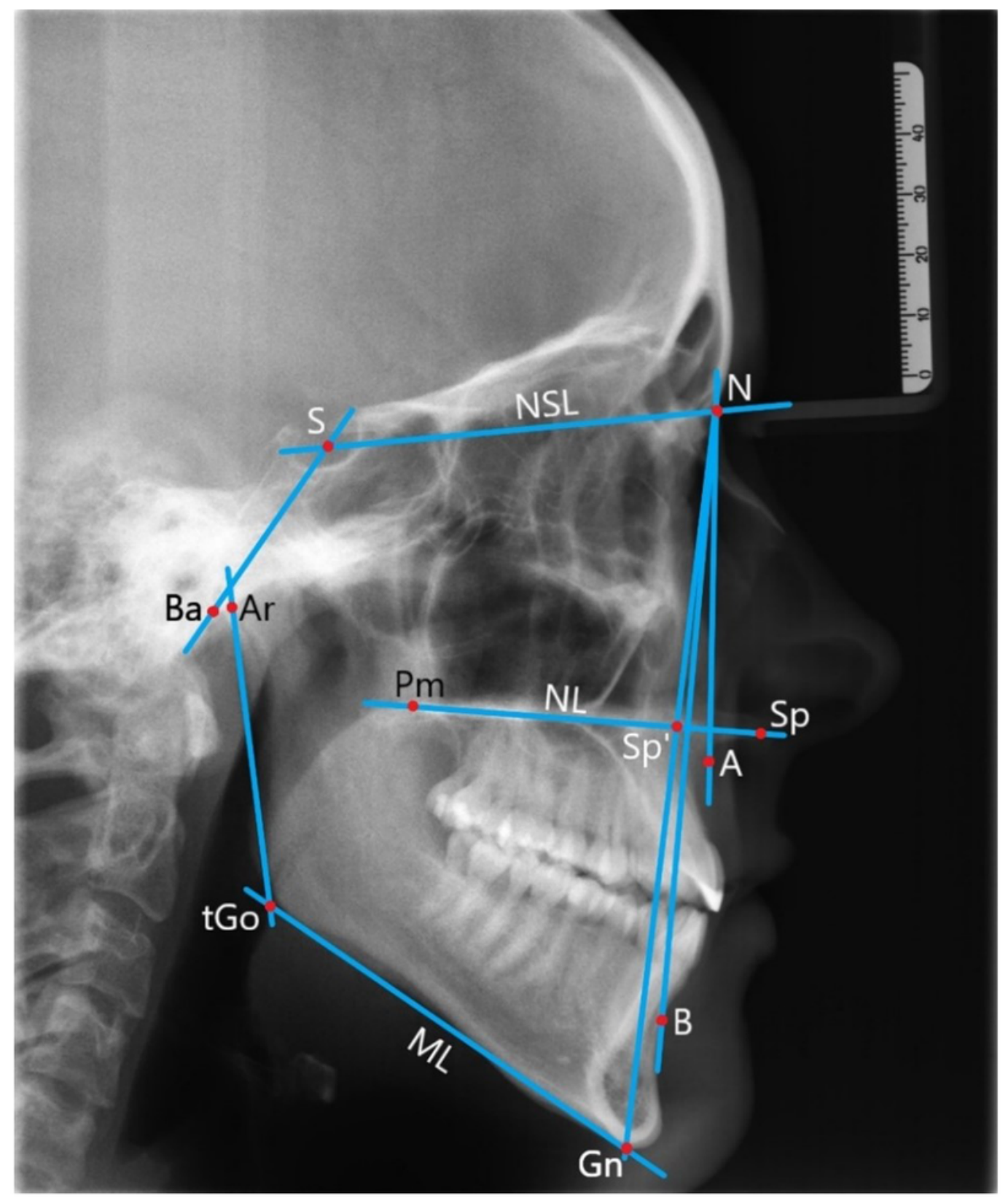

Figure 2: LC with cephalometric variables plotted: SNA angle, SNB angle, ANB angle, ML-NSL angle, NL-

NSL angle, ML-NL angle, NSBa angle, Gn-Go-Ar angle, Index $=\frac{N-S p r}{S p^{\prime}-G n} \times 100$.

\section{Figure 2}

See image above for figure legend 


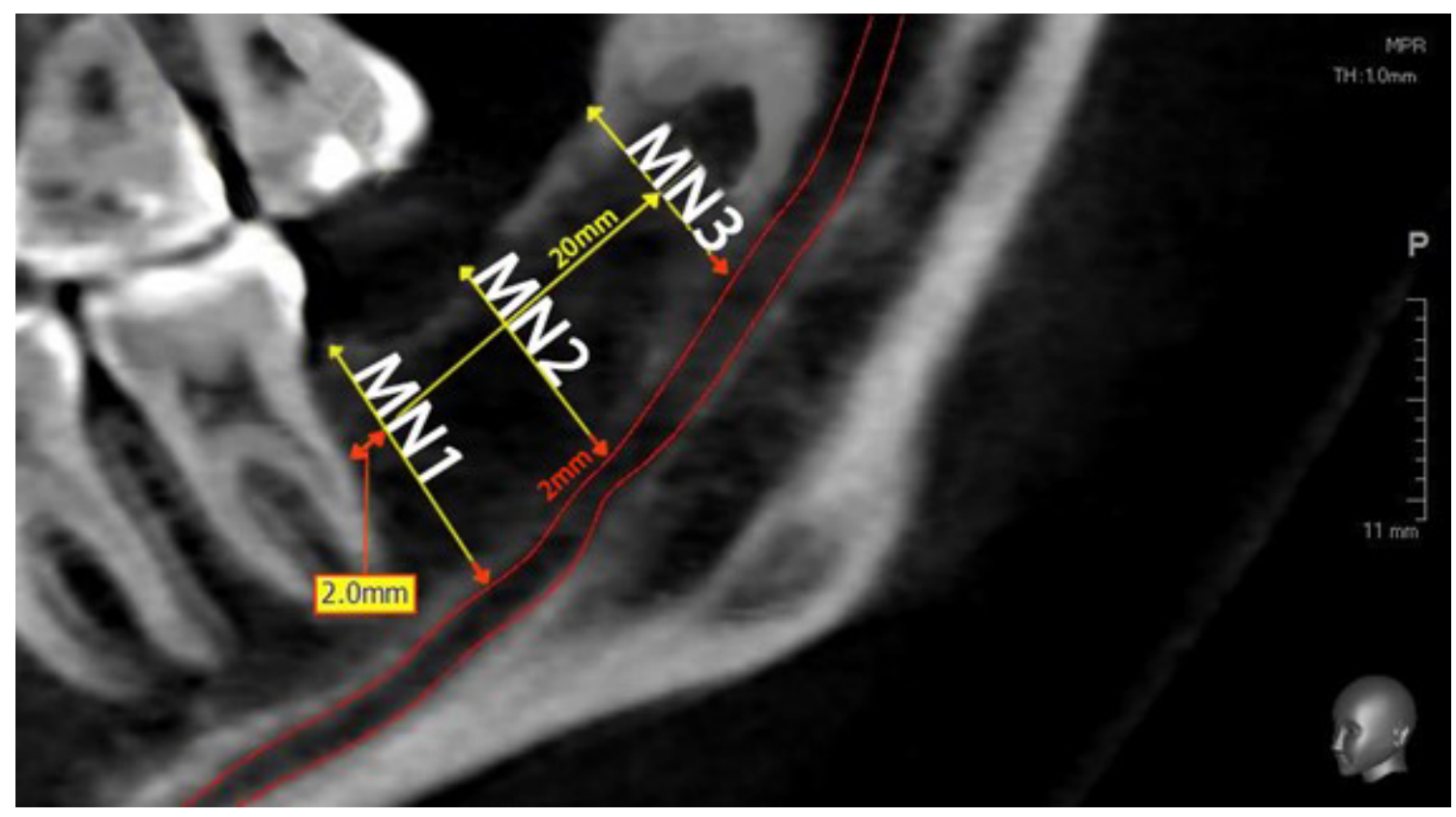

Figure 3

Sagittal section of the retromolar region in the DVT image with alveolar nerve marked in red and measuring points marked in yellow.

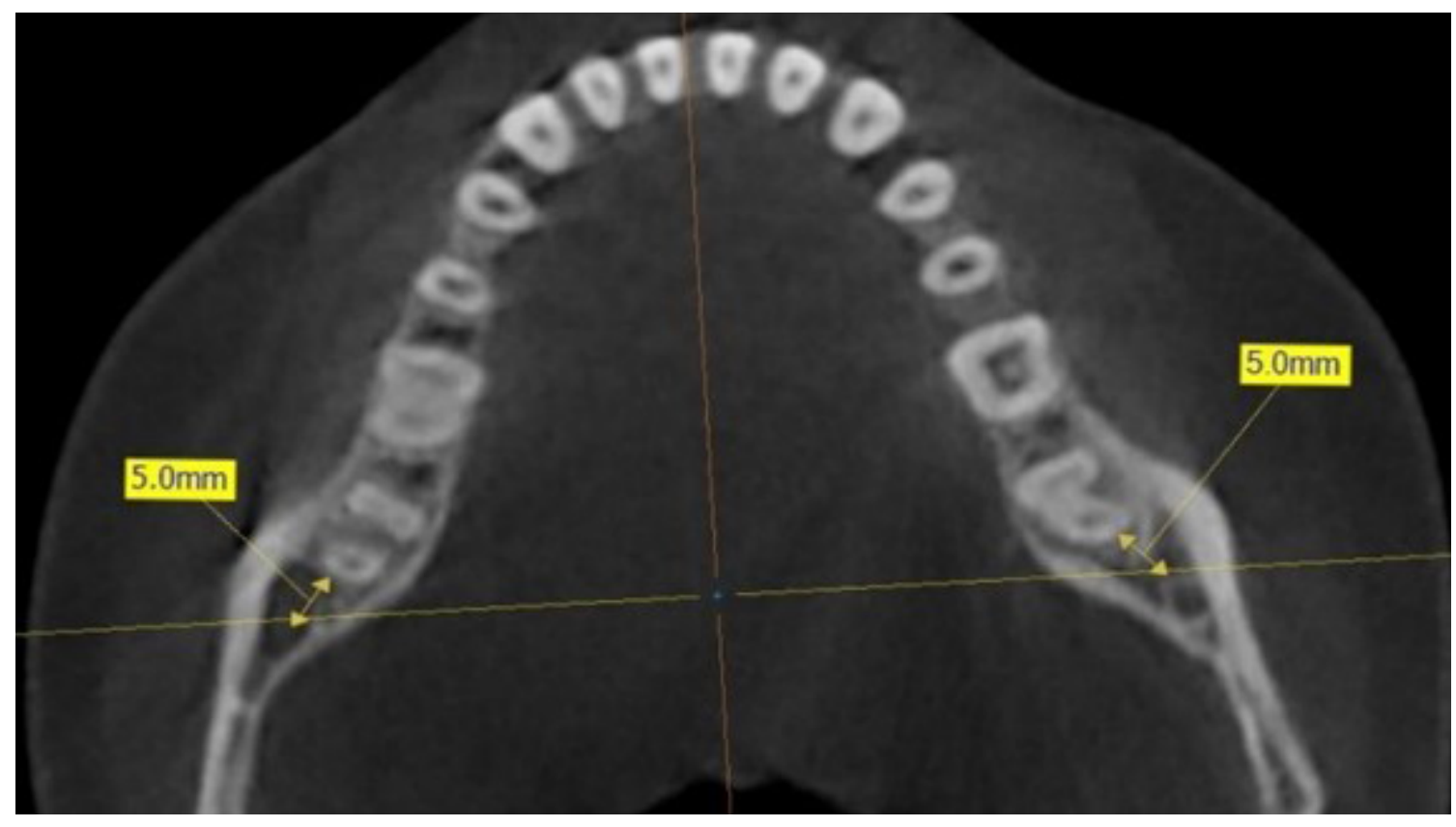

Figure 4

Axial view of the mandible in the DVT with marked distance of $5 \mathrm{~mm}$ distal to the last molar. The coronal view was adjusted using these distance markings. 


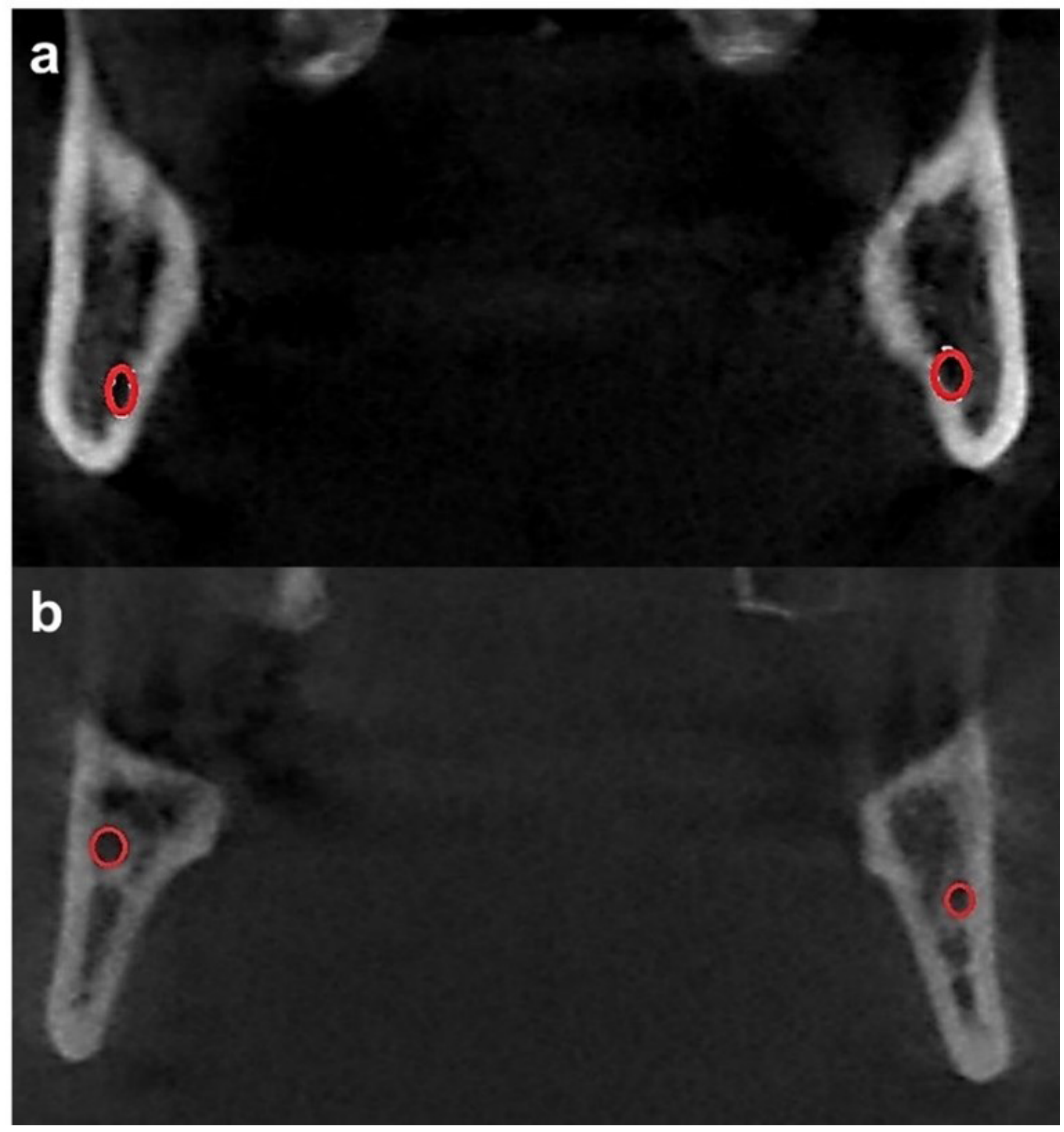

Figure 5

Coronal view of the mandible in the DVT. The lingually a) and buccally b) running inferior alveolar nerve is marked in red. 


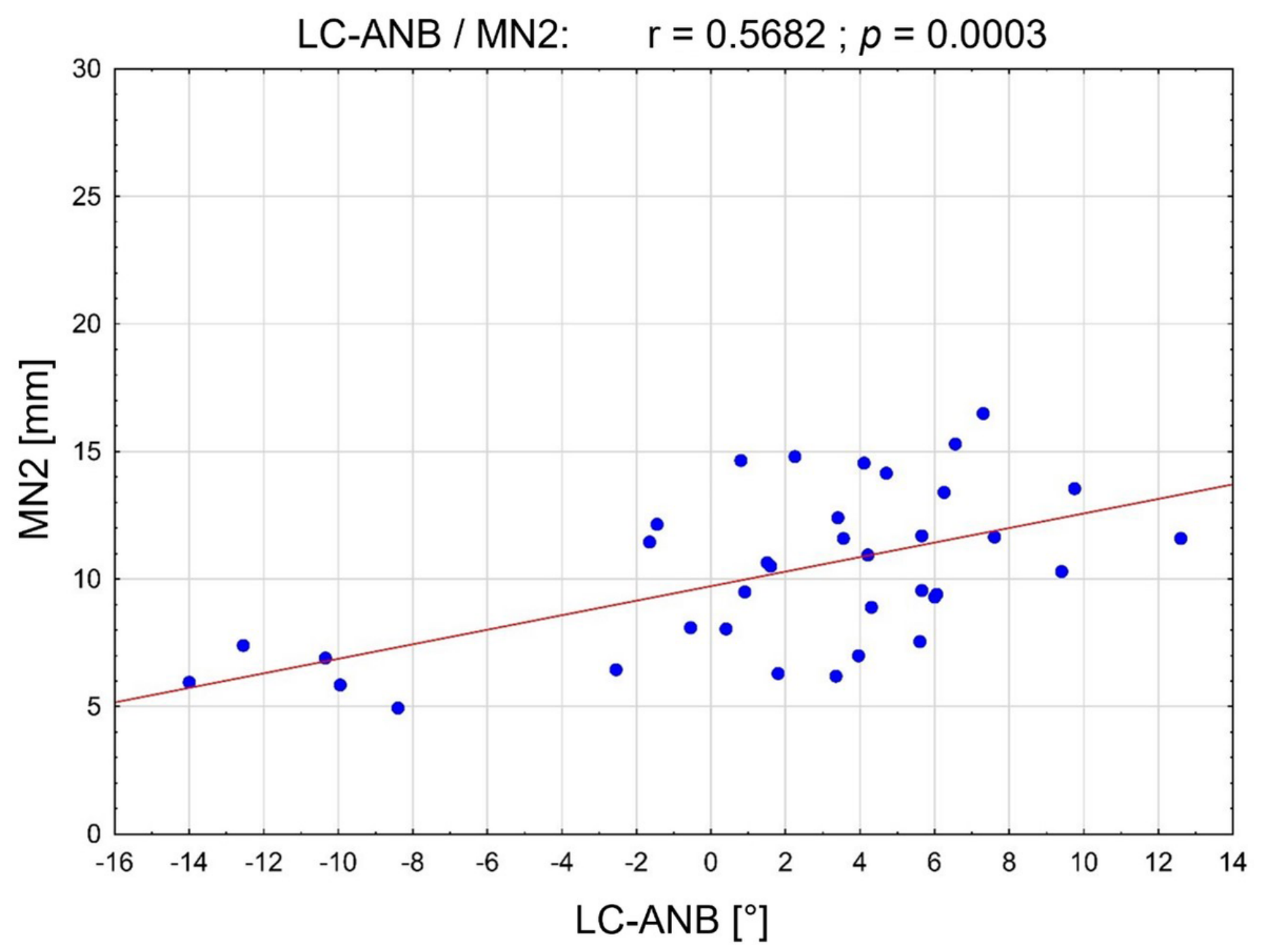

Figure 6

Scatterplot of the Pearson correlation between the ANB $\left[^{\circ}\right]$ (measured in LC) and the vertical position of the inferior aleveolar nerve MN2 [mm] (measured in CBCT). 


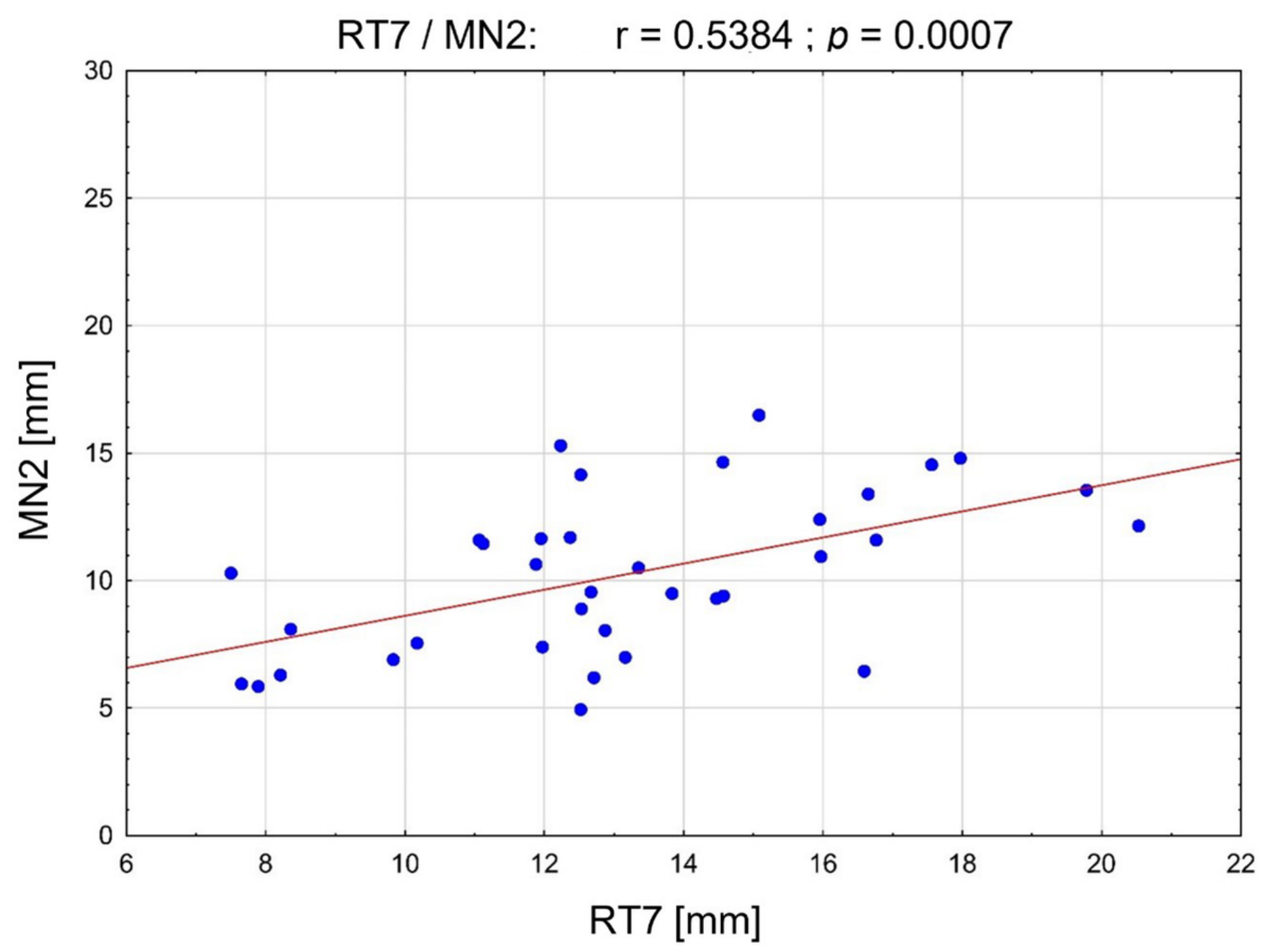

Figure 7

Scatterplot of the Pearson correlation between the distance WS7 [mm] (measured on OPT) and the vertical position of the inferior alveolar nerve MN2 [mm] (measured on CBCT). 


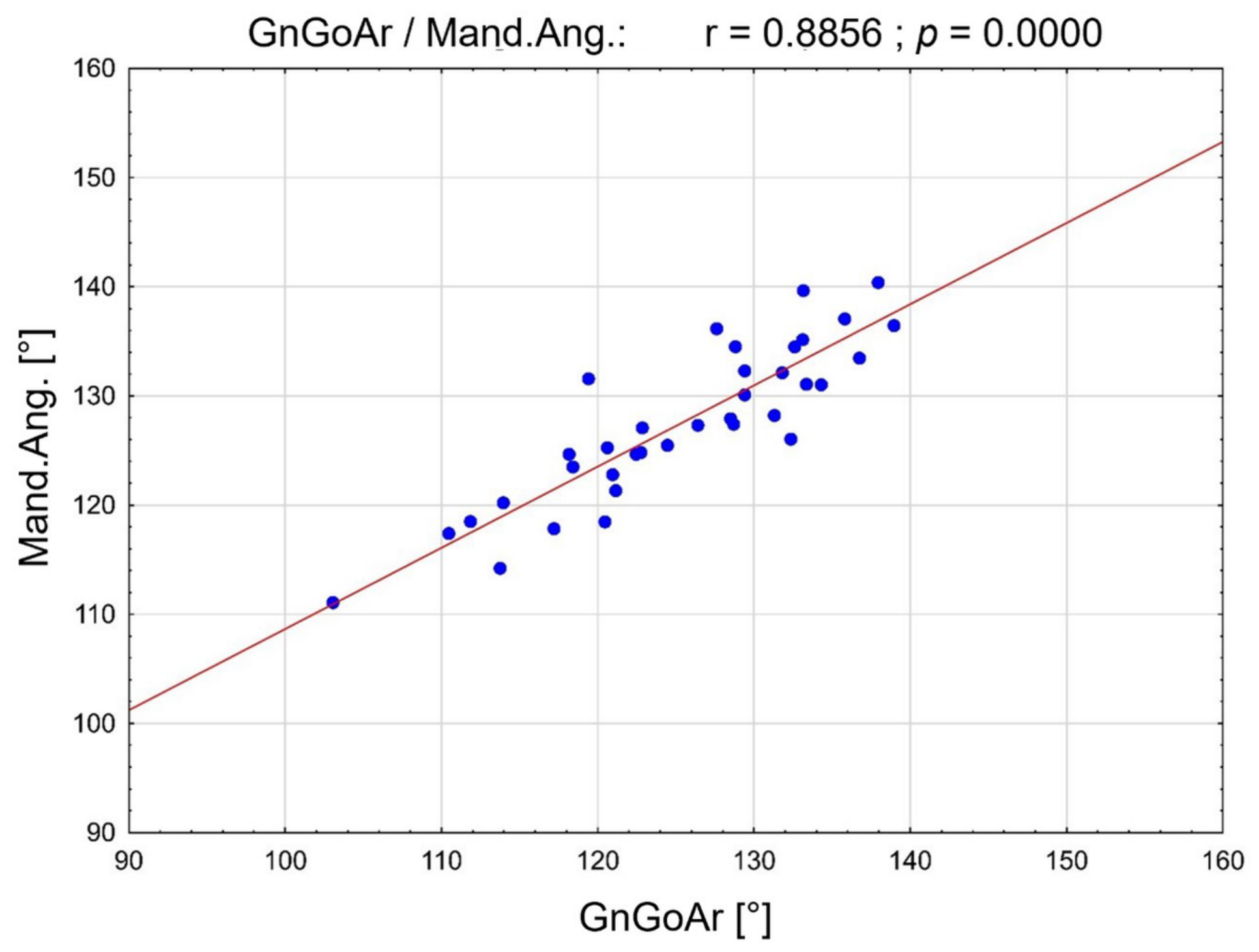

Figure 8

Scatterplot of the Pearson correlation between the Gn-Go-Ar $\left[^{\circ}\right]$ (measured in LC) and the Ang. Mand. $\left[^{\circ}\right]$ (measured in the OPT). 